The Global Health Network Collections • Part 3 Human Milk in Special Circumstances

20 Breastfeeding and the Use
of Medications

Thomas W. Hale, Prof, PhD, RPh, Teresa Ellen Baker, MD, FACOG

Published on: Apr 03, 2020 


\section{Breastfeeding and the Use of Medications}

Thomas W. Hale, Prof, PhD, RPh, and Teresa Ellen Baker, MD, FACOG

\section{Expected Key Learning Outcomes}

- The risks of medication transfer to human milk

- Considerations and recommendations for clinicians when prescribing medication to lactating women

- Measurement of infant exposure to medications

- Where to get further help and advice

\subsection{Introduction}

Human milk provides the infant's first and finest choice for protection against infectious organisms because it is perfectly suited to the infant's gastrointestinal (GI) tract. The numerous growth factors in human milk enhance growth and maturation of the infant's relatively permeable GI tract.

Medication use by pregnant and breastfeeding women has risen enormously over the last few decades, and it is estimated that between $40 \%$ and $90 \%$ of pregnant women take at least one medication during pregnancy [1], [2]. This increased frequency in medication use during pregnancy is likely to result in even more medications used during the postpartum period while the mother is breastfeeding.

A population-based study conducted during 1998-2002 found that while the prevalence of medication use decreased from $72 \%$ prior to pregnancy to $56 \%$ during pregnancy, it rose again to $78 \%$ in the postpartum period [3] . Several studies have found that the use of medication during the time from delivery of the placenta through the first few weeks after the delivery (puerperium) is high, ranging from $98-99 \%$ of all mothers [4]], []ㅡ.

Inevitably, the use of medications during lactation involves a level of complexity not usually encountered by most clinicians. In these instances, the risk-to-benefit analysis must include not only the health of the mother but that of the infant, who may or may not receive benefit, untoward side effects, or overt toxicity secondary to the mother's treatment.

We are now aware of many of the currently available medications that are significantly hazardous to the foetus or to the breastfed infant, and we universally try to avoid them. However, almost all drugs pass into human milk, with the potential to produce untoward side effects in the infant. This continues to occur today, even though we have more extensive knowledge of this area. The risk is generally less 
in older infants as they are generally less susceptible to most drugs present in milk and are more metabolically able to eliminate virtually any drug.

Fortunately, the human breast is relatively efficient at preventing high concentrations of many drugs and chemicals from entering into their compartments. Thus, the relative number of medications that are truly hazardous to a breastfeeding infant is rather low. This chapter discusses the entry of medications into human milk and their relative risks.

\subsection{Evaluating the Age of the Infant}

The age of the infant is one of the more critical elements in determining the sensitivity of the infant to various medications. In the first 2-3 days postpartum (the colostral phase), the alveolar structure of the breast is quite open and porous, thus permitting almost complete access of maternal proteins, lipids, immunoglobulins, and medications into the milk compartment. During this period, most drugs in milk reach equilibrium with the plasma compartment. However, at 4 days, as the alveolar epithelial cells begin to swell, the intercellular gaps close and the alveolar system becomes increasingly less porous. This results in dramatically lower drug levels in the milk compartment after the first week postpartum. Regardless of porosity, even during the early porous stage, the volume of milk produced and transferred to the infant is so small that the absolute clinical dose of medication transferred is often miniscule.

Premature infants are highly sensitive to medications and thus the risk to the infant is much higher. In instances where the infant is still in a neonatal intensive unit, some risks are acceptable because the nursing staff is closely monitoring the infant. If the infant has been discharged, mothers should be cautioned about potential side effects, such as apnoea and respiratory depression, that the parents must monitor at home.

In infants older than 6 months, most drugs pose less risk because the infant has developed significant renal function and respiratory control, and is more able to metabolically eliminate the drug. As the infant ages past 6 months, milk production in most mothers tends to wane with a decline in the volume of milk, thus less drug is delivered to the infant. After 18 months, the volume of milk is often negligible as is the risk of most drugs.

\subsection{Neonatal Pharmacokinetics}

Paediatric patients are generally referred to as "therapeutic orphans" due to the lack of pharmacokinetic studies in infants and young children. Less than $1 \%$ of all therapeutic agents have 
recommended dosing guidelines for the premature infant. Thus, in infants, comparing the dose of medication delivered via milk to a normal clinical dose is exceeding difficult because dosing regimens for this age group are often unavailable.

Oral medications present in milk must be absorbed via the GI tract. However, there are little or no data on the absorption of drugs in infants. A state of relative achlorhydria exists in the stomach in the first week postpartum. During the first few weeks of life, the $\mathrm{pH}$ of the stomach rises to a $\mathrm{pH}$ of 4.0, after which it slowly declines towards adult values over the next two years. Weak acids (e.g., phenobarbital) may have reduced absorption, while weak bases may have enhanced absorption. Since the infant's exposure is by the oral route, oral bioavailability of the medication is of paramount importance. As in adults, drugs with high first-pass clearance (e.g., morphine) are rapidly cleared from the portal circulation by the liver. Drugs with poor stability in the gut (e.g., aminoglycosides, insulin, heparin) are rapidly degraded in the stomach or intestine. Poor biliary function subsequently leads to poor lipid absorption and relative steatorrhea in premature infants, so lipidsoluble drugs presented in milk are likely to have poorer bioavailability.

Compared to adults, gastric emptying time is greatly prolonged in premature infants and in some cases may completely alter absorption kinetics; total body water content is higher in infants; protein binding is decreased in neonates; and the capacity of the liver for oxidative and conjugative metabolism is greatly reduced in neonates [6]. While the metabolic capacity of the liver is limited in the newborn, it rapidly increases and actually supersedes adult capacity in subsequent months [7]. Ultimately, the evaluation of the safety of drugs in breast milk depends on three major factors:

- Amount of medication present in milk

- Oral bioavailability of the medication

- Infant's ability to clear (remove from the body) the medication, thus preventing high therapeutic levels

While the amount present in milk has been published for some drugs, the ability of the infant to clear the medication renally and hepatically is highly variable and should be the subject of clinical evaluation. Infant clearance has been estimated to be $5 \%, 10 \%, 33 \%, 50 \%, 66 \%$, and $100 \%$ of adult maternal levels at 24-28, 28-34, 34-40, 40-44, 44-68, and > 68 weeks postpartum, respectively [ 8 ].

\subsection{Maternal Drug in Human Milk}

are not "trapped" in milk, but maintain a dynamic equilibrium to and from the maternal plasma. As such, advising mothers to "pump and discard" is not usually required to assist drug elimination; just waiting a few hours for the maternal plasma level to drop is equally efficacious. Advising mothers to 
breastfeed before taking the medication often works with medications with a short half life but not with those with a long half-life.

\subsection{Bioavailability}

The bioavailability of a medication generally refers to the amount of drug that reaches the systemic circulation after administration. Depending on the route of administration (oral, intravenous, intramuscular, subcutaneous or topical), medications must ultimately pass into the systemic circulation prior to reaching their intended site of action or the milk compartment. The poor bioavailability of many products reduces their level of exposure to breastfed infants. In some instances, some medications are unstable in the gastric milieu or are incompletely absorbed by infants. Most, but not all, topical medications are poorly absorbed transcutaneously, so they seldom attain significant plasma levels. The liver sequesters or metabolises many orally-administered medications preventing their entry into the plasma compartment. Because infants receive drugs via the mother's milk, oral bioavailability is of major importance in evaluating the potential risk to the infant. The absolute dose of a medication the infant receives via milk is a function of the drug's oral bioavailability; drugs with poor bioavailability are therefore preferable for breastfeeding mothers as their absorption by the infant is likely poor.

\subsection{Calculating Infant Exposure}

One of the simplest methods of determining the safety of the medication is to relate the weight normalized dose the infant receives via milk to that administered orally during infant therapy (where specific data are available). However, the most useful and accurate measure of exposure is to calculate the relative infant dose (RID), as follows.

The RID is generally expressed as a percentage of the mothers' dose. Its calculation provides a standardised method of relating the infant's dose to the maternal dose. In full term infants, Bennett [9] recommends that a RID of $>10 \%$ should be the theoretical "level of concern" for most medications. However, in premature infants, the "level of concern" may be lower depending on the medication. In this respect, it should be understood that neonates may have been exposed in utero to drugs taken by their mothers, and that in utero exposure may be an order of magnitude greater than that received via breast milk.

Finally, all medications enter the milk compartment. However, the vast majority of drugs do so at levels so low that the amount present is clinically irrelevant. Without exception, the use of medications by breastfeeding mothers automatically implies that some of those medications will transfer to the 
infant. The degree of risk to the infant requires an understanding of the pharmacokinetics of drug transfer into human milk. This review summarises what we presently understand and don't understand about the entry of drugs into human milk, and its clinical implications to newborn and premature infants. Knowing when to discontinue breastfeeding and when to support continued breastfeeding is of major importance to the mother and infant dyad.

\subsection{Review of Important Selected Drug Classes}

\subsubsection{Analgesics}

Analgesic drugs are the most commonly used medications by breastfeeding mothers, particularly in the early postnatal period. Consisting primarily of non-steroidal analgesics and opiates, millions of mothers annually use these drugs during breastfeeding. Table 20.1 provides an overview of analgesics in human milk.

\section{Nonsteroidal anti-inflammatory drugs (NSAIDs)}

Numerous NSAIDs exist, and many of them have been studied in breastfeeding mothers. However, ibuprofen (Advil) is perhaps the most preferred drug in this group. Ibuprofen is an ideal analgesic for breastfeeding mothers as the levels found in milk levels are very low. Less than $0.7 \%$ of the maternal dose is transferred daily to the infant [10]. The use of ketorolac (Toradol) is controversial. Previously, ketorolac was criticised for impeding platelet function. However, more recently, there is concern about the risk to the mother of acute renal injury, particularly in early postpartum or volume constricted patients. While ketorolac (Toradol) may cause bleeding problems in some postpartum women due to the inhibition of platelet aggregation, its drug levels in milk are insignificant. In a study of lactating women who received ketorolac $10 \mathrm{mg}$ orally four times a day, milk levels of ketorolac were not detectable in four of the 10 subjects [10]. In the remaining six subjects, the ketorolac concentration in milk 2 hours after dosing ranged 5.2-7.3 $\mu \mathrm{g} / \mathrm{L}$ on day 1 to $5.9-7.9 \mu \mathrm{g} / \mathrm{L}$ on day 2. In this study, ketorolac was administered orally rather than by intramuscular injection, which would avoid some of the firstpass effect, but even so, ketorolac may be considered moderately safe analgesic for breastfeeding mothers.

\section{Tab. 20.1 Analgetics in human milk.}




\begin{tabular}{|c|c|c|c|}
\hline Drug & $\begin{array}{l}\text { Relative } \\
\text { infant dose } \\
(\%)\end{array}$ & $\begin{array}{l}\text { Lactation } \\
\text { risk } \\
\text { category* }\end{array}$ & References \\
\hline Acetaminophen & $8.8-24.2$ & Compatible & {$[65],[66],[67],[68]$} \\
\hline Aspirin & $<2.5-10.8$ & $\begin{array}{l}\text { Compatible in low doses. } \\
\text { Prolonged use could be } \\
\text { problematic, so other } \\
\text { analgesics are preferred }\end{array}$ & [69], [70], [71] \\
\hline Celecoxib & $0.3-0.7$ & $\begin{array}{l}\text { Compatible. Observe infant } \\
\text { for diarrhoea }\end{array}$ & {$[11],[12]$} \\
\hline Ibuprofen & $0.1-0.7$ & Compatible & [72], [73], [74] \\
\hline Ketorolac & 0.2 & Compatible & {$[10]$} \\
\hline Naproxen & 3.3 & $\begin{array}{l}\text { Compatible. Avoid chronic } \\
\text { use. Observed infant for } \\
\text { diarrhoea }\end{array}$ & [75], [76] \\
\hline Indomethacin & 1.2 & $\begin{array}{l}\text { Probably compatible. Avoid } \\
\text { chronic use. Observed } \\
\text { infant for diarrhoea }\end{array}$ & [77], [78] \\
\hline Morphine & $9-35$ & $\begin{array}{l}\text { Probably compatible. } \\
\text { Observe for sedation, } \\
\text { constipation, and apnoea }\end{array}$ & {$[13],[79],[80]$} \\
\hline Hydromorphone & 0.67 & $\begin{array}{l}\text { Probably compatible. } \\
\text { Observe for sedation, } \\
\text { constipation, and apnoea }\end{array}$ & [81] \\
\hline Hydrocodone & $2.21-3.7$ & $\begin{array}{l}\text { Probably compatible. } \\
\text { Observe for sedation, } \\
\text { constipation, and apnoea }\end{array}$ & [82], [83] \\
\hline Oxycodone & $1.0-8$ & $\begin{array}{l}\text { Probably compatible. } \\
\text { Observe for sedation, } \\
\text { constipation, and apnoea }\end{array}$ & [17], [84], [85] \\
\hline
\end{tabular}




\begin{tabular}{|l|l|l|l|}
\hline Codeine & $0.6-8.1$ & $\begin{array}{l}\text { Probably compatible. } \\
\text { Observe for sedation, } \\
\text { constipation, and apnoea }\end{array}$ & [71], [16], [86] \\
\hline Fentanyl & $2.9-5$ & Probably compatible & [87], [88], [89] \\
\hline *Lactation risk categories derived from Hales' Medication and Mothers' Milk, 2016 & \\
\hline
\end{tabular}

Older studies of celecoxib (Celebrex) suggest it is a safe analgesic for breastfeeding mothers. In a study of women receiving $200 \mathrm{mg}$ daily, celecoxib levels in milk averaged $66 \mu \mathrm{g} / \mathrm{L}$ [11]. The daily intake by an infant has been estimated to be approximately $20 \mu \mathrm{g} / \mathrm{kg} / \mathrm{day}$ [12]. Using these data, the RID was $0.34 \%$ of the maternal dose. Plasma levels of celecoxib in two infants studied were undetectable $(<10$ $\mathrm{ng} / \mathrm{mL})$.

\section{Opiates}

Opiates for pain control include mild to strong opiates, such as hydrocodone, oxycodone, oxymorphone, fentanyl, sufentanil, and morphine. Opioids are often used for acute pain after cesarean section or for other procedures in breastfeeding mothers. Morphine is generally the preferred opioid used in breastfeeding mothers because it has poor oral bioavailability $(26 \%)$ in the infant and a low RID of 9.1\% [1] $]$. However, hydrocodone and oxycodone are more commonly used worldwide. Hydrocodone is minimally transferred into milk. In a more recent study, hydrocodone and hydromorphone levels were measured in 125 breast milk samples obtained from 30 women receiving hydrocodone $0.14-0.21 \mathrm{mg} / \mathrm{kg} /$ day (10-15 mg/day) to alleviate postpartum pain [14]. Neonates received $1.6 \%$ of the maternal weight-adjusted hydrocodone dosage; when combined with hydromorphone, the total median opiate dosage from breast milk was $0.7 \%$ of a therapeutic dosage for older infants. Standard postpartum dosages of hydrocodone were considered to be acceptable for women nursing newborns. However, there are reports of adverse events in infants exposed to hydrocodone via breast milk, and all opioids should be used with caution in newborns [푸].

Since 2005, use of codeine has declined due to the death of an infant whose mother was taking codeine while breastfeeding [16]. Both codeine and oxycodone are less favourable opioids because they have unpredictable metabolism (via CYP 2D6 enzyme), produce active metabolites, and cause CNS depression in infants [17]. In a cohort of mothers using oxycodone, codeine, and acetaminophen for pain during lactation, reports of infant sedation were $20.1 \%, 16.7 \%$, and $0.5 \%$, respectively [1]ㅡ.

All opioids should be used with caution in breastfeeding mothers, particularly women with premature or unstable infants, with close monitoring of the infant for sedation and apnoea. Doses should be 
moderate to low and used for short periods only.

\subsubsection{Anti-Infectives}

\section{Antibiotics}

Virtually all antibiotics have been studied to some degree in breastfeeding mothers (Table 20.2). The most commonly used drugs are the penicillins and cephalosporins. Due to high polarity, this drug group is largely excluded from the milk compartment and RIDs are generally quite low. The macrolide family, such as erythromycin, azithromycin, and clarithromycin, produce low levels in breast milk. Following a dose of erythromycin $2 \mathrm{~g}$ daily, drug levels in milk varied from 1.6-3.2 mg/L of milk [1지. Azithromycin transfer to milk is minimal and produces a clinical dose to the infant of approximately $0.4 \mathrm{mg} / \mathrm{kg} / \mathrm{day}[\underline{19}]$.

Data have suggested an association of the macrolide, azithromycin with pyloric stenosis in the newborn infant following postnatal maternal ingestion [20]. As a group, macrolides are probably compatible with breastfeeding, particularly after 6 weeks postpartum. Some caution is recommended with erythromycin early postnatally.

\section{Antifungals}

Nystatin, commonly used for candida infections, is poorly absorbed orally, and thus its transfer into milk is nil. Fluconazole transfers significantly into human milk with a relative infant dose of $16.4 \%$ to $21.5 \%$ [21] although this is still subclinical in infants. While this RID is higher than the $10 \%$ notional safety range, fluconazole has proven relatively safe in many cases, and the dose received via breast milk is far less than clinical doses commonly used directly in infants.

\section{Sulphonamides}

Sulfamethoxazole, is commonly used in combination with trimethoprim for various infections, particularly urinary tract and resistant staphylococcus infections. The RID of sulfamethoxazole and of

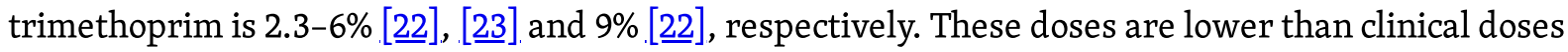
typically used in infants. However, sulphonamides should not be used in infants with hyperbilirubinemia or glucose-6-phosphate dehydrogenase deficiency. 


\subsubsection{Antidepressants}

Almost all current antidepressants have been studied in breastfeeding mothers. Numerous studies suggest that levels of these agents in milk are low and that they are probably acceptable during breastfeeding ( Table 20.3).

\section{Tricyclic antidepressants (TCAs)}

While useful this group of antidepressant is poorly accepted by patients due to anticholinergic symptoms, such as xerostomia, blurred vision, and sedation. As such, TCAs are less often used than other antidepressant drugs. The RID of amitriptyline is less than $1.5 \%$ of the maternal dose [24]. Studies to date have been unable to detect amitriptyline in the infant's plasma. Doxepin should be avoided due to reported hypotonia, poor suckling, vomiting, and jaundice [25] .

\section{Selective serotonin reuptake inhibitors (SSRIs)}

SSRIs are presently one of the most commonly used medications in breastfeeding mothers, and the most commonly studied drug group in breastfeeding mothers in the last decade.

The many published clinical studies on the use of sertraline, fluoxetine, and paroxetine by breastfeeding mothers clearly indicate that the transfer of these medications into human milk is low and uptake by the infant is even lower. Side effects in infants include withdrawal following intrauterine exposure, although there are few reported problems following use of these drugs by breastfeeding mothers.

\begin{tabular}{|c|c|c|c|}
\hline Drug & $\begin{array}{l}\text { Relative } \\
\text { infant dose } \\
\text { (\%) }\end{array}$ & $\begin{array}{l}\text { Lactation } \\
\text { risk } \\
\text { category* }\end{array}$ & References \\
\hline Amoxicillin & 1 & $\begin{array}{l}\text { Compatible. Observe infant } \\
\text { for diarrhoea or thrush }\end{array}$ & [90] \\
\hline Cephalexin & $0.4-1.47$ & $\begin{array}{l}\text { Compatible. Observe infant } \\
\text { for diarrhoea or thrush }\end{array}$ & [91] \\
\hline
\end{tabular}




\begin{tabular}{|c|c|c|c|}
\hline Cefotaxime & $0.4-0.3$ & $\begin{array}{l}\text { Compatible. Observe infant } \\
\text { for diarrhoea or thrush }\end{array}$ & [91] \\
\hline Dicloxacillin & $0.4-1.4$ & $\begin{array}{l}\text { Compatible. Observe infant } \\
\text { for diarrhoea or thrush }\end{array}$ & [90] \\
\hline Azithromycin & 5.9 & $\begin{array}{l}\text { Compatible. Observe infant } \\
\text { for diarrhoea or thrush }\end{array}$ & [19] \\
\hline Clarithromycin & 2 & $\begin{array}{l}\text { Compatible. Observe infant } \\
\text { for diarrhoea or thrush }\end{array}$ & [92] \\
\hline Erythromycin & $1.4-1.7$ & $\begin{array}{l}\text { Compatible. Use postnatally } \\
\text { associated with infantile } \\
\text { hypertrophic pyloric } \\
\text { stenosis. Observe for } \\
\text { diarrhoea or thrush }\end{array}$ & [90], [20], [93] \\
\hline Ciprofloxacin & $0.4-6.34$ & $\begin{array}{l}\text { Compatible. One case of } \\
\text { pseudomembranous colitis } \\
\text { reported. Observe for } \\
\text { diarrhoea or candida } \\
\text { overgrowth }\end{array}$ & [94], [95], [96] \\
\hline Doxycycline & $4-13.3$ & $\begin{array}{l}\text { Compatible for short term } \\
\text { use (<3 weeks). Avoid } \\
\text { chronic dosing. Observe } \\
\text { infant for diarrhoea or } \\
\text { candida overgrowth }\end{array}$ & [97], [98] \\
\hline Tetracycline & 0.6 & $\begin{array}{l}\text { Compatible for short-term } \\
\text { use. Oral absorption low. } \\
\text { Observe infant for } \\
\text { diarrhoea or candida } \\
\text { overgrowth }\end{array}$ & [90], [99], [100] \\
\hline Clindamycin & $0.9-1.8$ & $\begin{array}{l}\text { Compatible. One case of } \\
\text { pseudomembranous colitis } \\
\text { reported. Observe infant } \\
\text { for diarrhoea or candida } \\
\text { overgrowth }\end{array}$ & [101], [90], [102], [103] \\
\hline
\end{tabular}




\begin{tabular}{|l|l|l|}
\hline Metronidazole & 12.6-13.5 & $\begin{array}{l}\text { Compatible with moderate } \\
\text { transfer. No adverse effects }\end{array}$ \\
& $\begin{array}{l}\text { reported in exposed } \\
\text { infants. Dose via milk less } \\
\text { than therapeutic dose. May } \\
\text { impose bitter taste to milk. }\end{array}$ \\
& $\begin{array}{l}\text { For } 2 \text { g single oral dose, } \\
\text { discard milk for 12-24 h }\end{array}$ \\
& \\
&
\end{tabular}

*Lactation risk categories derived from Hales' Medication and Mothers' Milk, 2016

Sertraline appears to be the preferred SSRI. More than 50 infants have been evaluated across the many studies, which indicate that sertraline levels in breast milk and infant plasma are low to undetectable.

Fluoxetine has also been studied in at least 50 breastfeeding infants. Fluoxetine transfers into human milk in relatively higher concentrations, with reported levels as high as $9 \%$ of the maternal dose [26]. Clinically relevant plasma levels in infants have been reported due to the long half-life of fluoxetine's active metabolite. Consequently, with its higher RID (versus sertraline), fluoxetine is not as preferable unless lower doses are used during pregnancy and early postpartum. In reality, fluoxetine is associated with a low incidence of untoward effects, and mothers who cannot tolerate other SSRIs should be maintained on this drug while breastfeeding.

\begin{tabular}{|c|c|c|c|}
\hline Drug & $\begin{array}{l}\text { Relative } \\
\text { infant dose } \\
(\%)\end{array}$ & $\begin{array}{l}\text { Lactation } \\
\text { risk } \\
\text { category* }\end{array}$ & References \\
\hline Bupropion & $0.11-2.0$ & Compatible & $\begin{array}{l}\text { [106], [107], [108], [109], } \\
{[110]}\end{array}$ \\
\hline Citalopram & $3.5-5.4$ & $\begin{array}{l}\text { Compatible. Observe for } \\
\text { somnolence }\end{array}$ & $\begin{array}{l}\text { [111], [112], [27], [113], [114], } \\
\text { [115], [116] }\end{array}$ \\
\hline Escitalopram & $5.2-7.9$ & Compatible & [117], [118], [28] \\
\hline Fluoxetine & $1.6-14.6$ & Compatible & $\begin{array}{l}{[119],[120],[121],[122],[26],} \\
{[123],[124],[125]}\end{array}$ \\
\hline
\end{tabular}




\begin{tabular}{|l|l|l|l|}
\hline Fluvoxamine & $0.3-1.4$ & Compatible & $\begin{array}{l}{[126],[127],[128],[129],} \\
{[130],[131]}\end{array}$ \\
\hline Paroxetine & $1.2-2.8$ & Compatible & $\begin{array}{l}{[132],[133],[134],[135],} \\
{[136],[137],[138]}\end{array}$ \\
\hline Sertraline & $0.4-2.2$ & Compatible & $\begin{array}{l}{[139],[140],[141],[142],} \\
{[143],[144]}\end{array}$ \\
\hline Trazodone & & & {$[145]$} \\
\hline Venlafaxine & 2.8 & Compatible & {$[146],[147]$} \\
\hline *Lactation risk categories derived from Hales' Medication and Mothers' Milk, 2016 & \\
\hline & $6.8-8.1$ & Compatible &
\end{tabular}

There is moderate transfer of citalopram and its new congener, escitalopram to breast milk. In a study of seven women receiving an average of citalopram $0.41 \mathrm{mg} / \mathrm{kg} / \mathrm{day}$, the average RID was 3.7\% [27]. Low concentrations of citalopram were found in the infants' plasma ( 2 and $2.3 \mu \mathrm{g} / \mathrm{L})$. While no untoward effects have been noted in published studies, two cases of somnolence have been reported to the manufacturer. In another study of eight breastfeeding women taking an average of escitalopram 10 $\mathrm{mg} /$ day, the total RID of escitalopram and its metabolite was reported to be $5.3 \%$ [2요. Currently, escitalopram is probably preferred over citalopram for breastfeeding mothers.

Neonatal withdrawal symptoms have been commonly reported in infants $(30 \%)$ exposed in utero to SSRIs with a shorter half-life (paroxetine, sertraline). With fluoxetine [29 ], [30], sertraline, and paroxetine [31], these symptoms, which occur early postnatally, consist of poor adaptation, irritability, jitteriness, and poor gaze control. Most clinicians do not treat neonatal withdrawal symptoms unless they are severe. For a mother taking SSRIs, breastfeeding the infant is certainly advised. However, the antidepressant concentration in the milk is usually too low to be effective in treating the withdrawal symptoms.

\subsubsection{Immune Modulating Agents}

The use of immunosuppressants and immune modulating agents in breastfeeding mothers is poorly understood. While there are few studies on these agents and their transfer to human milk, this does not preclude their use in breastfeeding mothers. The newer monoclonal antibody preparations are becoming increasingly important. 


\section{Methotrexate}

Methotrexate is a potent and potentially dangerous folic acid antagonist used in immune diseases, particularly rheumatic disorders. It is also used as abortifacient in tubal pregnancies. Methotrexate is secreted into breast milk at low levels. Following an oral dose of $22.5 \mathrm{mg}$ to a single patient, the methotrexate concentration in breast milk two hours post-dose was $2.6 \mu \mathrm{g} / \mathrm{L}$ of milk [32]. The cumulative excretion of methotrexate in the first 12 hours was only $0.32 \mu \mathrm{g}$ in milk. Based on these findings, it was concluded that methotrexate therapy in breastfeeding mothers would not pose a contraindication to breastfeeding. However, methotrexate may be retained in human tissues (particularly neonatal GI cells and ovarian cells) for long periods (months). While the methotrexate concentration in human milk is minimal, it is recommended to pump and discard the mother's milk for a minimum of 4 days after dosing is stopped. Due to the toxicity of this agent, the length of time that the milk should be discarded is dependent on the dose level and duration.

\section{Methylprednisolone}

Pulsed dose methylprednisolone is one of the mainstays of therapy in multiple sclerosis (MS). Fortunately, the transfer of corticosteroids into human milk is poor at best. Studies of radiolabelled prednisolone have found that the total dose after 48 hours was only $0.14 \%$ of the maternal dose [ $\underline{33}$ ]. However, in cases of multiple sclerosis, massive intravenous doses (e.g., 1-2 g) may be used. Data suggest levels in milk reduce rapidly, and that mothers can safely breastfeed as early as 8-12 hours following intravenous use of high dose methylprednisolone [34] .

\subsubsection{Monoclonal Antibodies}

Engineered immunoglobulins are becoming more common in the treatment of autoimmune and neoplastic diseases. These drugs target specific proteins, such as tumour necrosis factor, while leaving others untouched. The molecules are very large ( $>100$ kilodaltons) and consequently have a low RID in the order of $1-2 \%$ [35], [36], [37]. These drugs should theoretically have poor oral bioavailability due to destruction by proteases in the infant's stomach. However, several researchers have postulated that monoclonal antibody drugs might be absorbed via the immunoglobulin G-transporting neonatal Fc receptor $(\mathrm{FcRn})$ that is expressed in intestinal cells of adults and foetuses [37]. Knowledge in this area continues to evolve, but the current evidence suggests these products are probably compatible with breastfeeding. 


\subsubsection{Recreational Drugs}

Drugs that enter the central nervous system (CNS) readily cross the blood brain barrier, which is similar to the lactocyte barrier. Hence, most CNS active drugs will enter milk to a higher degree. Women are strongly advised to avoid using these medications while breastfeeding, as they all pose some risk to the infant. The more relevant question of whether a woman who uses these drugs should even consider breastfeeding needs to be evaluated on a case-by-case basis. However, some drugs used for recreational purposes are also of clinical use. For example, amphetamine drugs used for hyperactivity disorders are similar in structure to methamphetamine and other amphetamines used recreationally. In cases of drugs approved for clinical use, mothers can continue to breastfeed with some caution.

\section{Alcohol}

Alcohol readily enters the milk compartment and produce milk to plasma ratios of 1.0 or equivalent to the plasma compartment. While equal to levels in the plasma, the absolute clinical dose to the infant is still quite low. For example, a study of twelve breastfeeding mothers who ingested ethanol $0.3 \mathrm{~g} / \mathrm{kg}$ exhibited an average maximum ethanol concentration of $320 \mathrm{mg} / \mathrm{L}$ in their milk [ $\underline{38}]$. Importantly, ethanol has been shown to strongly inhibit oxytocin release and decrease milk delivery to the infant [39]. A woman of average size will reduce her milk alcohol level by $15-20 \mathrm{mg} / \mathrm{dL} /$ hour, which equates to metabolising a 'standard drink' (14 g of pure ethanol) in about 2 hours [ $\underline{40}]$.

\section{Tobacco}

Aside from tar and other combustion products, tobacco smoking results in high maternal plasma levels of nicotine and its metabolite cotinine. With a longer half-life than nicotine, pharmacologically active cotinine is much less potent than nicotine [41]. Cotinine levels are useful for tracking nicotine metabolism but are not necessarily representative of second-and third-hand contact with tobacco residues, of the relative safety of using nicotine replacement products, or of exposure to the many other dangerous chemicals in tobacco.

Studies have demonstrated a linear relationship between smoking rates in the mother, nicotine levels

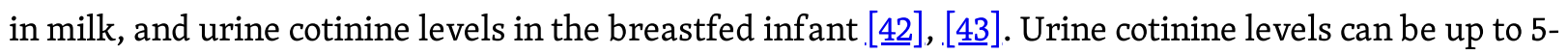
times greater in breastfed infants of mothers who smoke than in non-breastfed infants whose mothers smoke [44]. Even second-hand smoke can increase the risk of otitis media, respiratory tract infections, and asthma in the baby [4ㄷ]. The benefits of breastfeeding off sets some of this risk and the current recommendations are for the mother to continue regardless of her smoking habits, but never to smoke in the presence of the infant. 


\section{Marijuana/cannabis}

Small to moderate secretion of marijuana into breast milk has been documented [46]. In one study, milk levels of the principal psychoactive compound in marijuana THC were $340 \mu \mathrm{g} / \mathrm{L}$ in one mother who consumed marijuana 7-8 times daily, and $105 \mu \mathrm{g} / \mathrm{L}$ in another mother who consumed marijuana once daily [46]. Analysis of breast milk from a chronic heavy marijuana user revealed an 8-fold accumulation of THC in breast milk compared to plasma, although the dose received was apparently insufficient to produce significant side effects in the infant.

Studies have shown significant absorption and metabolism of marijuana in infants, although longterm sequelae are conflicting. In a study of 27 women who smoked marijuana routinely during breastfeeding, no differences were noted in the growth and mental and motor development of their infants compared to the norm [ㅍ]]. Conversely, in another study, maternal use of marijuana during first trimester of pregnancy and during breastfeeding was shown to be associated with a slight decrease in infant motor development at one year of age, especially when used during the first month of lactation [48]. Interestingly, in this study, the use of marijuana during pregnancy and lactation had no detectable effect on inf ant mental development at one year of age, suggesting that the behavioural advantages of human milk may offset some of the detrimental effects of marijuana exposure.

Significant new evidence has begun to emerge suggesting that exposure to THC in pregnancy or chronic use in adolescence and early adulthood may result in changes to the endocannabinoid system in the brain [뇨], [499]. This system is partially responsible for regulating mood, reward, and goal directed behaviour. Adverse neurobehavioral effects have not yet been demonstrated in infants exposed to THC exclusively through breast milk [47]. Nevertheless, mothers should be strongly advised to not use marijuana during pregnancy or breastfeeding.

\section{Heroin and methadone}

While morphine is generally a preferred analgesic for breastfeeding mothers, its diacetyl derivative, heroin is relatively dangerous. Heroin doses can in some instances be extraordinarily high, thus leading to high plasma levels and potentially significant transfer of morphine into the milk compartment. As with other opiates, tolerance follows from chronic use, and addicts may end up using extraordinarily large doses. It is the high dose of heroin that poses the greatest risk to the breastfed infant.

Heavily dependent heroin users should be advised against breastfeeding and their infants transitioned to formula. Methadone is a potent and very long-acting opiate analgesic used primarily to prevent withdrawal in opiate addicts. Unlike heroin, methadone produces only inactive metabolites. A large volume of distribution results in a low RID (2-6\%) and infant exposure is further reduced by its 


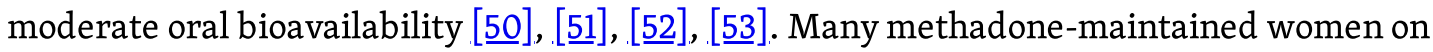
extraordinarily high doses (>150 mg/ day) have breastfed their infants successfully. Infants become quite tolerant of these doses via milk. However, they also become quite dependent, so sudden withdrawal should be avoided by the mother.

\section{Cocaine}

Cocaine is a potent CNS stimulant that is likely to readily transfer to human milk, although there are no available substantiating data. Estimates vary regarding the degree of cocaine contamination in the breast milk, ranging from 1-10\% of the maternal dose [두], [ㅌ5]. Cocaine is rapidly metabolised to several inactive metabolites, and drug screens generally detect these for days following use. Mothers who are drug-screen positive may be able to breastfeed safely if a long enough time period has occurred following exposure. Inactive metabolites are excreted in the urine and breast milk for up to 7 days following initial exposure to the drug. Breast milk is likely to be free of cocaine after 24 hours, but infants can become drug-screen positive due to metabolite ingestion.

\subsubsection{Drugs Altering Milk Supply}

Milk production is highly dependent on the timing and frequency of breastfeeding. However, some mothers still produce insufficient milk despite attempting to breastfeed often and thoroughly. Any factor that interferes with adequate breast emptying, including poor infant attachment, infrequently emptying, and sleeping through the night, may ultimately lead to a drop in milk production. The cause of this is largely unknown, but a reduction in plasma prolactin levels may play a role. Frequently pumping or breastfeeding may reverse this situation, but not always, and in these cases, galactagogues may prove beneficial.

Milk production in the mother is highly dependent on elevated levels of prolactin. While not known for certain, milk production appears to wane once prolactin levels fall below approximately $50 \mathrm{ng} / \mathrm{mL}$. The classic galactagogues used today cause the release and maintenance of higher levels of prolactin in the breastfeeding mother, thereby stimulating milk production.

\section{Metoclopramide}

Metoclopramide is a promotility drug that effectively blocks dopamine receptors in the pituitary. In some mothers metoclopramide has been shown to effectively increase milk production [ [ $\underline{6}$ ], [므] , [ $\underline{58}$ ], [59]. While it is difficult to predict which women will respond with elevated milk production, women with low prolactin levels are ideal candidates. The prolactin-stimulating effect of metoclopramide 
appears to be dose-related. The standard dose of 10-15 mg given orally three times per day has been found efficacious. Response is usually rapid, with the mother noticing significant increases of milk volume within 24-48 hours. The amount of metoclopramide in milk rarely exceeds $160 \mu \mathrm{g} / \mathrm{L}$, even at the highest maternal doses [무] .

Unfortunately, metoclopramide crosses the blood-brain barrier, and drug-induced depression is a common side effect in mothers who use this medication. Other problems include extrapyramidal symptoms, gastric cramping, and tardive dyskinesia. Some mothers also experience a rebound drop in milk production if they discontinue the drug without slowly tapering the dose.

\section{Domperidone}

Domperidone has been successfully used worldwide to increase milk production [므], [61], [므]. This drug is also a dopamine antagonist but, unlike metoclopramide, does not cross the blood-brain barrier. Levels of domperidone in milk are extraordinarily low (around $1.2 \mathrm{ng} / \mathrm{mL}$ ) and oral bioavailability is less than $20 \%$ [미].

Domperidone may in rare cases prolong the QT interval, particularly in older males. The potassium channel receptor is partially responsible for repolarising cardiac muscle cells and, thus by blocking potassium channels, the use of domperidone may cause arrhythmias. Although this side effect is infrequent, this drug should not be used in mothers with pre-existing rhythm disorders, especially prolonged QT syndrome. Importantly, the QT syndrome is dose related, and doses greater than 60 $\mathrm{mg} /$ day should be avoided. Data have shown that plasma levels of prolactin are almost identical following doses of $30 \mathrm{mg} /$ day or $60 \mathrm{mg} /$ day [63] , suggesting that doses higher than 30-60 mg/day may not further increase prolactin levels.

\subsection{Summary}

All medications transfer into human milk to some degree, although they are almost always subclinical, and the mother should in most instances be advised to continue breastfeeding. However, certain classes of drugs, including anticancer agents, antimetabolite agents, radioactive drugs, and those that specifically inhibit milk production, present a relatively greater risk and the clinician should be aware of these.

In each case, the clinician must first evaluate the relative risk to the infant by considering the absolute or relative dose transferred via milk to the infant as well as the disadvantages to the infant of not breastfeeding. Higher rates of GI syndromes, upper respiratory tract infection, and other diseases are well-documented in infants fed formula compared with those who receive breast milk. 
The infant's health status must be closely evaluated. Infants at greater risk of harm by medications include those who are premature, weak, have apnoea, or those with poor renal clearance, while older infants are at less risk. Because the milk volume decreases over time, particularly after 6 months, infants are exposed to reduced doses of maternal medicines over time. After 12 months postpartum, there is often a significant reduction in milk volume, and the infant's ability to metabolise and renally excrete drugs has developed close to that of the adult.

With most drugs, the amount of medication delivered to the infant via milk is much less than $4 \%$ of the maternal dose, and the amount the infant actually absorbs is likely less. In healthy infants, this amount is often easily tolerated without untoward effects. However, as the RID rises above 7-10\%, and the toxicity of the medication increases, the clinician should be more cautious in recommending breastfeeding. Brief interruptions in breastfeeding may avoid infant exposure to high levels of drug in milk. Partial formula feeding may be used to reduce exposure of the infant while allowing the mother to continue partially breastfeeding.

In almost all situations, there are numerous medications that can be safely used for specific syndromes and the clinician should be open to choosing those drugs with lower RIDs. This is not always difficult to do, as there are now hundreds of studies concerning medications and their use in breastfeeding mothers. Almost invariably a more suitable drug can be chosen so that a mother can continue to breastfeed her infant [뎌].

Most importantly, breast milk is the most beneficial nutrition a mother can give her infant. The immunological and health benefits are overwhelmingly documented in the literature. Interrupting breastfeeding for unsound reasoning, such as to take a relatively safe medication, should be avoided where possible.

\section{Key Points}

- All medications transfer into human milk to some degree, although most will have little or no effect upon the infant, and the mother should in most instances be advised to continue breastfeeding

- Certain classes of drugs, including anticancer agents, antimetabolite agents, radioactive drugs, and those that specifically inhibit milk production, present risks the clinician should be aware of

- The risk/benefit analysis needs to consider the health of the mother and the infant. Clinicians should evaluate the relative risks by considering the drug dose transferred to the infant versus the disadvantages to the infant of not breastfeeding. Greater caution is needed for premature infants who are highly sensitive to medications 
- Relative infant dose (RID is the standard measure of infant exposure to milk transferred drugs). In the case of an RID below 7-10\%, clinicians should consider advising mothers to continue breastfeeding

- For most medical conditions, a drug is available that allows the mother to continue to breastfeed her infant. Up-to-date information for medication and lactation can be found here: http://www.medsmilk.com

\section{Citations}

1. Abdul HB, Torok J, Mezey G. Drug Utilization Study during Pregnancy. Acta Pharm Hung. 1995; 65(3): 69-75

2. Rubin JD, Ferencz C, Loffredo C. Use of Prescription and Non-Prescription Drugs in Pregnancy. The Baltimore-Washington Infant Study Group. J Clin Epidemiol. 1993; 46(6): 581-589

3. Berard A, Ramos F, Blais L, et al. Medications and Pregnancy: A Population-Based Study. Pharmacoepidemiol Drug Saf. 2005; 14(Suppl 2): S19-S20

4. Lucas A, Lucas PJ, Baum JD. Differences in the Pattern of Milk Intake between Breast and Bottle Fed Infants. Early Hum Dev. 1981; 5(2): 195-199

5. Passmore CM, McElnay JC, D’Arcy PF. Drugs Taken by Mothers in the Puerperium: Inpatient Survey in Northern Ireland. Br Med J (Clin Res Ed). 1984; 289 (6458): 1593-1596

6. Besunder JB, Reed MD, Blumer JL. Principles of Drug Biodisposition in the Neonate. A critical evaluation of the pharmacokinetic-pharmacodynamic interface (Part II). Clin Pharmacokinet. 1988; 14(5): 261-286ヒ

7. Morselli PL. Clinical Pharmacology of the Perinatal Period and Early Infancy. ClinPharmacokinet. 1989; 17 Suppl 1: 13-28: 13-28

8. Begg EJ. Clinical Pharmacology Essentials. The Principles behind the Prescribing Process. Auckland. Adis Int. 2000; 34-35

9. Bennett PN. Use of the Monographs on Drugs. In: Drugs and Human Lactation. Amsterdam: Elsevier; 1996: 442-443 10. Wischnik A, Manth SM, Lloyd J, et al. The Excretion of Ketorolac Tromethamine into Breast Milk after Multiple Oral Dosing. Eur J Clin Pharmacol. 1989; 36 (5): 521-524

11. Hale TW, McDonald R, Boger J. Transfer of Celecoxib into Human Milk. J Hum Lact. 2004; 20(4): $397-403 \subseteq$ 
12. Knoppert DC, Stempak D, Baruchel S, et al. Celecoxib in Human Milk: A Case Report. Pharmacotherapy. 2003; 23(1): 97-100

13. Feilberg VL, Rosenborg D, Broen CC, et al. Excretion of Morphine in Human Breast Milk. Acta Anaesthesiol Scand. 1989; 33(5): 426-428

14. Sauberan JB, Anderson PO, Lane JR, et al. Breast milk hydrocodone and hydromorphone levels in mothers using hydrocodone for postpartum pain. Obstet Gynecol. 2011; 117(3): 611-617 15. Meyer D, Tobias JD. Adverse Effects Following the Inadvertent Administration of Opioids to Infants and Children. Clin Pediat. 2005; 44(6): 499-503 16. Koren G, Cairns J, Chitayat D, et al. Pharmacogenetics of Morphine Poisoning in a Breastfed Neonate of a Codeine-Prescribed Mother. Lancet. 2006; 368 (9536): $704 \triangleq$

17. Lam J, Kelly L, Ciszkowski C, et al. Central Nervous System Depression of Neonates Breastfed by Mothers Receiving Oxycodone for Postpartum Analgesia. J Pediatr. 2012; 160: 33-37

18. Knowles JA. Drugs in Milk. Pediatr Currents. 1972; 21: 28-32

19. Kelsey JJ, Moser LR, Jennings JC, et al. Presence of Azithromycin Breast Milk Concentrations: A Case Report. Am J Obstet Gynecol. 1994; 170(5 Pt 1): 1375-1376

20. Sorensen HT, Skriver MV, Pedersen L, et al. Risk of Infantile Hypertrophic Pyloric Stenosis after Maternal Postnatal Use of Macrolides. Scand J Infect Dis. 2003; 35(2): 104-106

21. Force RW. Fluconazole Concentrations in Breast Milk. Pediatr Infect Dis J. 1995; 14(3): 235-236 22. Miller RD, Salter AJ. The Passage of Trimethoprim/ Sulphamethoxazole into Breast Milk and its Significance. In: Daikos GK, ed. Progress in Chemotherapy. Proceedings of the Eight International Congress of Chemotherapy, Athens, 1973. Athens: Hellenic Society for Chemotherapy; 1974: 687-691 23. Chung AM, Reed MD, Blumer JL. Antibiotics and Breast-Feeding: A Critical Review of the Literature. Paediatr Drugs. 2002; 4(12): 817-837

24. Bader TF, Newman K. Amitriptyline in Human Breast Milk and the Nursing Infant's Serum. Am J Psychiatry. 1980; 137(7): 855-856

25. Frey OR, Scheidt P, von Brenndorff AI. Adverse Effects in Aa Newborn Infant Breast-Fed by a Mother Treated with Doxepin. Ann Pharmacother. 1999; 33 (6): 690-693

26. Kristensen JH, Ilett KF, Hackett LP, Yapp P, Paech M, Begg EJ. Distribution and Excretion of Fluoxetine and Norfluoxetine in Human Milk. Br J Clin Pharmacol. 1999; 48(4): 521-527 
27. Rampono J, Kristensen JH, Hackett LP, et al. Citalopram and Demethylcitalopram in Human Milk; Distribution, Excretion and Effects in Breast Fed Infants. Br J Clin Pharmacol. 2000; 50(10): 263-268

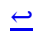

28. Rampono J, Hackett LP, Kristensen JH, et al. Transfer of Escitalopram and its Metabolite Demethylescitalopram into Breastmilk. Br J Clin Pharmacol. 2006; 62(3): 316-322

29. Chambers CD, Johnson KA, Dick LM, et al. Birth Outcomes in Pregnant Women Taking Fluoxetine. New Engl J Med. 1996; 335(14): 1010-1015

30. Spencer MJ, Escondido CA. Fluoxetine Hydrochloride (Prozac) Toxicity in a Neonate. Pediatrics. 1993; 92 (5): 721-722

31. Stiskal JA, Kulin N, Koren G, et al. Neonatal Paroxetine Withdrawal Syndrome. Arch Dis Child Fetal Neonatal Ed. 2001; 84(2): F134-F135

32. Johns DG, Rutherford LD, Leighton PC, et al. Secretion of Methotrexate into Human Milk. Am J Obstet Gynecol. 1972; 112(7): 978-980

33. McKenzie SA, Selley JA, Agnew JE. Secretion of Prednisolone into Breast Milk. Arch Dis Child. 1975; 50 (11): 894-896

34. Cooper SD, Felkins K, Baker TE, et al. Transfer of Methylprednisolone Iinto Breast Milk in a Mother with Multiple Sclerosis. J Hum Lact. 2015; 31(2): 237-239

35. Vasiliauskas EA, Church JA, Silverman N, et al. Case Report: Evidence for Transplacental Transfer of Maternally Administered Infliximab to the Newborn. Clin Gastroenterol Hepatol. 2006; 4(10): $1255-1258 \subseteq$

36. Cornillie F, Shealy D, D’Haens G, et al. Infliximab Induces Potent Anti-Inflammatory and Local Immunomodulatory Activity but no Systemic Immune Suppression in Patients with Crohn's Disease. Aliment Pharmacol Therapeut. 2001; 15(4): 463-473

37. Fritzsche J, Pilch A, Mury D, et al. Infliximab and Adalimumab Use during Breastfeeding. J Clin Gastroenterol. 2012; 46(8): 718-719

38. Mennella JA. Regulation of Milk Intake after Exposure to Alcohol in Mothers' Milk. Alcohol Clin Exp Res. 2001; 25(4): 590-593

39. Coiro V, Alboni A, Gramellini D, et al. Inhibition by Ethanol of the Oxytocin Response to Breast Stimulation in Normal Women and the Role of Endogenous Opioids. Acta Endocrinol (Copenh). 1992; 126(3): $213-216 \sqsubseteq$ 
40. Ho E, Collantes A, Kapur BM, et al. Alcohol and Breast Feeding: Calculation of Time to Zero Level in Milk. Biol Neonate. 2001; 80(3): 219-222

41. Dwoskin LP, Teng L, Buxton ST, et al. (S)-(-)-Cotinine, the Major Brain Metabolite of Nicotine, Stimulates Nicotinic Receptors to Evoke [3H]Dopamine Release from Rat Striatal Slices in a CalciumDependent Manner. J Pharmacol Exper Therapeut. 1999; 288(3): 905-911

42. Woodward A, Grgurinovich N, Ryan P. Breast Feeding and Smoking Hygiene: Major Influences on Cotinine in Urine of Smokers' Infants. J Epidemiol Community Health. 1986; 40(4): 309-315

43. Dahlström A, Lundell B, Curvall $M$ et al. Nicotine and cotinine concentrations in the nursing mother and her infant. Acta Paediatr Scand 1990; 79(2): 142- 147

44. Becker AB, Manfreda J, Ferguson AC, et al. BreastFeeding and Environmental Tobacco Smoke Exposure. Arch Pediatr Adolesc Med. 1999; 153(7): 689- 691

45. Kum-Nji P, Meloy LD, Keyser-Marcus L. The Prevalence and Effects of Environmental Tobacco Smoke Exposure among Inner-City Children: Lessons for Pediatric Residents. Acad Med. 2012; 87(12): $1772-1778 \subseteq$

46. Perez-Reyes M, Wall ME. Presence of Delta9-Tetrahydrocannabinol in Human Milk. N Engl J Med. 1982; 307(13): 819-820

47. Tennes K, Avitable N, Blackard C, et al. Marijuana: Prenatal and Postnatal Exposure in the Human. NIDA Res Monogr. 1985; 59: 48-60

48. Astley SJ, Little RE. Maternal Marijuana Use during Lactation and Infant Development at One Year. Neurotoxicol Teratol. 1990a; 12(2): 161-168

49. Volkow ND, Baler RD, Compton WM, et al. Adverse Health Effects of Marijuana Use. New Engl J Med. 2014; 370(23): 2219-2227

50. Blinick G, Inturrisi CE, Jerez E, et al. Methadone Assays in Pregnant Women and Progeny. Am J Obstet Gynecol. 1975; 121(5): 617-621

51. Wojnar-Horton RE, Kristensen JH, Yapp P, et al. Methadone Distribution and Excretion into Breast Milk of Clients in a Methadone Maintenance Programme. Br J Clin Pharmacol. 1997; 44(6): $543-547 \subseteq$

52. Geraghty B, Graham EA, Logan B, et al. Methadone Levels in Breast Milk. J Hum Lactat. 1997; 13(3): $227-230 \subseteq$ 
53. Begg EJ, Malpas TJ, Hackett LP, et al. Distribution of R- and S-Methadone into Human Milk during Multiple, Medium to High Oral Dosing. Br J Clin Pharmacol. 2001; 52(6): 681-685

54. Sarkar M, Djulus J, Koren G, Motherisk Program. When a Cocaine-Using Mother Wishes to Breastfeed: Proposed Guidelines. Therapeutic drug monitoring. 2005; 27(1): 1-2

55. Winecker RE, Goldberger BA, Tebbett IR, et al. Detection of Cocaine and its Metabolites in Breast Milk. Journal of forensic sciences. 2001; 46(5): 1221- $1223 \boxminus$

56. Kauppila A, Kivinen S, Ylikorkala O. A Dose Response Relation between Improved Lactation and Metoclopramide. Lancet. 1981; 1(8231): 1175-1177

57. Kauppila A, Arvela P, Koivisto M, et al. Metoclopramide and Breast Feeding: Transfer into Milk and the Newborn. Eur J Clin Pharmacol. 1983; 25(6): 819- $823 \subseteq$

58. Budd SC, Erdman SH, Long DM, et al. Improved Lactation with Metoclopramide. A case report. Clin Pediatr (Phila). 1993; 32(1): 53-57

59. Ehrenkranz RA, Ackerman BA. Metoclopramide Effect on Faltering Milk Production by Mothers of Premature Infants. Pediatrics. 1986; 78(4): 614-620

60. Hofmeyr GJ, van Iddekinge B. Domperidone and Lactation. Lancet. 1983; 1(8325): $647 \subseteq$

61. Brouwers JR, Assies J, Wiersinga WM, et al. Plasma Prolactin Levels after Acute and Subchronic Oral Administration of Domperidone and of Metoclopramide: A Cross-Over Study in Healthy Volunteers. Clin Endocrinol. 1980; 12(5): 435-440

62. da Silva OP, Knoppert DC, Angelini MM, et al. Effect of Domperidone on Milk Production in Mothers of Premature Newborns: A Randomized, Double-Blind, Placebo-Controlled Trial. CMAJ. 2001; 164(1): 17- $21 \leftrightharpoons$

63. Wan EW, Davey K, Page-Sharp M, et al. Dose-Effect Study of Domperidone as a Galactagogue in Preterm Mothers with Insufficient Milk Supply, and its Transfer into Milk. Br J Clin Pharmacol. 2008; 66(2): $283-289 \leftrightharpoons$

64. Hale TW, Rowe HR. Medications and Mothers' Milk. Hale Publishing LP; 2016: $2016 \subseteq$ 